\title{
Rheological and electrical analysis in carbon nanofibre reinforced polypropylene composites
}

\begin{tabular}{|r|l|}
\hline Journal: & Journal of Polymer Science Part B: Polymer Physics \\
\hline Manuscript ID: & Draft \\
\hline Watey - Manuscript type: & Full Papers \\
\hline Complete List of Authors: & $\begin{array}{l}\text { Paleo, Antonio; University of Minho, IPC - Institute for Polymers and } \\
\text { Composites } \\
\text { Silva, Jorge; Case Western Reserve University, Dept. of Macromolecular } \\
\text { Science and Engineering } \\
\text { Hattum, Ferrie; Institute for Polymers and Composites, } \\
\text { Lanceros-Mendez, Senentxu; University of Minho - Campus de Gualtar, } \\
\text { Department of Physics; } \\
\text { Ares, Ana; University of A Coruña, Grupo de Polímeros. Departamento de } \\
\text { Física }\end{array}$ \\
\hline Keywords: & \begin{tabular}{l} 
nanocomposites, rheology, conductive network, extrusion \\
\hline
\end{tabular} \\
\hline
\end{tabular}

\section{SCHOLARONE ${ }^{m}$}

Manuscripts 


\section{Rheological and electrical analysis in carbon nanofibre reinforced polypropylene composites}

\section{A. J. Paleo, J. Silva, F. W. J. van Hattum, S. Lanceros-Méndez and A. I. Ares}

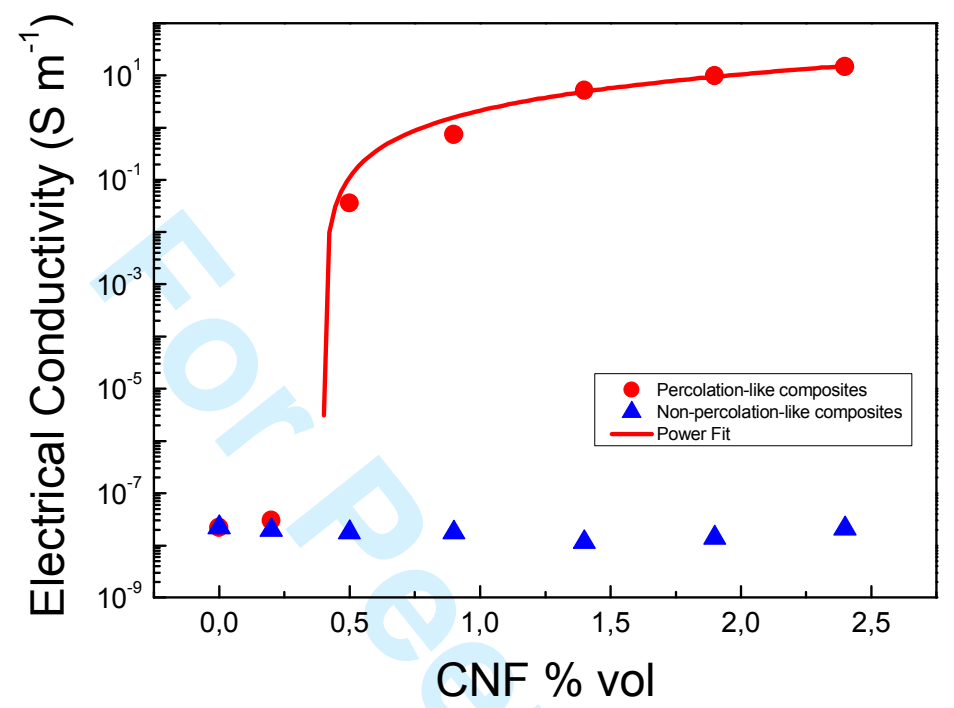

Two different carbon nanofibers were incorporated in in the same polypropylene by twinscrew extrusion. Electrically, the two carbon nanofiber based composites demonstrated to have different response: non-conducting and conducting as a function of volume fraction concentration. A large difference in the rheological behavior of both composites has been measured. Furthermore, after comparing electrical conductivity and rheological analysis, it is concluded that $\mathrm{G}^{\prime} / \mathrm{G}^{\prime \prime}$ is the most appropriate rheological parameter for comparing with electrical behavior. 
Authors: A. J. Paleo, J. Silva, F. W. J. van Hattum, S. Lanceros-Méndez and A. I. Ares

Title: Rheological and electrical analysis in carbon nanofibre reinforced polypropylene composites

\author{
Affiliations and address: \\ Antonio J. Paleo and F. W. J. van Hattum \\ IPC - Institute for Polymers and Composites, University of Minho, Campus de Azurém, \\ 4800-058 Guimarães, Portugal \\ J. Silva
}

Dept. of Macromolecular Science and Engineering, Case Western Reserve University, CLiPS

- Center for Layered Polymeric Systems, Kent Hale Smith Bldg., Room \# 3412100 Adelbert

Rd.

Cleveland, OH 44106-7202, USA

Senentxu Lanceros-Méndez

Center/Department of Physics, University of Minho, Campus de Gualtar, 4710-057 Braga, Portugal

A. I. Ares

Grupo de Polímeros. Departamento de Física. Universidade de A Coruña. Laboratorio de Polímeros. E.U.P. Avda 19 Febrero, s/n 15405- Ferrol, España.

\title{
Corresponding author:
}

Antonio J. Paleo

Telephone : (+351) 253510320

fax : (+351) 253510339

e-mail : antonio.vieito@dep.uminho.pt 


\begin{abstract}
Two different types of carbon nanofibers (CNF) were incorporated in the same polypropylene (PP) matrix by twin-screw extrusion. The electrical characterization of both CNFs / PP composites as a function of volume fraction show different electrical performance: conducting and non-conducting. The objective of this work is to study the rheological behaviour of both composites with the aim of relating it to the electrical behaviour. The results indicate that the rheological behaviours are different, suggesting that rheology differentiates the microstructural variations responsible for the electrical performance. Furthermore, the main rheological parameters were correlated to the electrical conductivity. The results show that $\mathrm{G}^{\prime} / \mathrm{G}^{\prime \prime}$ and $\mathrm{G}^{\prime}$ are the most sensitive parameters when compared to the onset of electrical percolation. Finally, in spite of the intrinsic measuring differences between electrical and rheological analysis, the two calculated thresholds are very similar: $\sim 0.5$ for the rheological and $\sim 0.4$ for the electrical.
\end{abstract}

KEYWORDS polypropylene, carbon nanofibers, electrical conductivity, rheological parameters, percolation

\title{
INTRODUCTION
}

Several nanostructures composed of graphitic layers, including nanographene platelets (NGPs), carbon nanofibers (CNFs) and nanotubes (CNTs) are currently the focus of intense investigation. CNFs in particular have a unique morphology in which exposed graphene edge planes are placed on the outer surface of the fiber. ${ }^{1}$ Their outer diameter, which ranges from 50 to $200 \mathrm{~nm}$, is slightly larger than CNTs. The inner diameters and lengths range from 30 to $90 \mathrm{~nm}$ and from 50 to $100 \mu \mathrm{m}$, respectively. ${ }^{2,3}$ Furthermore, their excellent electrical, thermal and mechanical characteristics as well as their simple incorporation and dispersion into polymers at a lower cost in comparison to carbon nanotubes, have converted CNFs into an object of study in several fields of materials science. ${ }^{4,5}$

An important area of application of carbon nanofibers is in the field of composite materials. By incorporating relatively small loadings of CNFs in a polymer matrix, electrically 
conductive composites can be produced, while at the same time increasing its mechanical properties. Some of the final uses of these CNFs based polymer composites are electrostatic dissipative (ESD), electromagnetic shielding (EMI) and radio frequency interference (RFI) materials. $^{6,7}$

Up to now, the majority of research in CNTs and CNFs based polymer composites has been motivated by the importance of several key-factors for the development of conducting and structural multifunctional materials: composites morphology, analysis of dispersion and distribution of nanofillers in the polymer, polymer-nanofiller interactions and the lowest loading required for conductive network formation. ${ }^{4,8-11}$

Additionally, it has been commonly established that rheological analysis, besides being a method to study viscoelastic properties to assess processing behavior, provides insights on the interaction between carbon nanostructures and polymer in the melt state. ${ }^{12,13}$ Kharchenko et. al characterized the transport property transitions in multiwall nanotubes (MWNT) dispersed in polypropylene (PP). In their study the electrical threshold (0.0025 volume fraction) precedes the rheological threshold (0.01 volume fraction), based on the rheological analysis of the inverse of loss tangent $\left(\mathrm{G}^{\prime} / \mathrm{G}^{\prime \prime}\right) .{ }^{14}$ By plotting $\mathrm{G}^{\prime}$ as a function of nanotube loading in single-walled carbon nanotube (SWNT) / poly(methyl methacrylate) (PMMA) nanocomposites, Du et. al reported a rheological threshold of $0.12 \mathrm{wt} \%$, whereas a value of $0.39 \mathrm{wt} \%$ was obtained for the electrical threshold. In this study, the onset of viscoelastic behavior was explained as the loading from which the distance between nanotube clusters is shorter than the size of the polymer chain causing restriction of polymer motion. ${ }^{12}$ More recently, in their attempt to compare quantitatively electrical with rheological values in polystyrene (PS) containing MWCNTs, Kota et. al conclude that the storage modulus, G', and $\mathrm{G}^{\prime} / \mathrm{G}^{\prime \prime}$, rheological parameters related to the elastic load transfer, are more sensitive to 
the onset of electrical percolation than $\eta^{*}$ and $\mathrm{G}^{\prime \prime}$, rheological parameters related to dissipation mechanisms. ${ }^{15}$

Though several attempts to correlate conductivity with rheological properties have been discussed in CNT based polymer nanocomposites, there are only few studies focused on the investigation of percolation thresholds through electrical and rheological analysis of CNF based polymer nanocomposites. ${ }^{16}$ Furthermore, to our knowledge, there is no investigation evaluating rheological and electrical properties in electrical and non-electrical conducting composites with the aim of discussing if rheological analysis allows distinguishing electrical conducting from electrical isolating response in this kind of systems. Besides, in order to compare electrical with rheological thresholds, the most sensitive rheological parameter is calculated. The work has been performed with two different CNFs incorporated in the same polypropylene (PP) matrix through twin-screw extrusion under the same processing conditions.

\section{EXPERIMENTAL}

\section{Materials and Methods}

A PP powder, Borealis EE002AE, was used as polymer matrix. The two types of stacked-cup CNFs used in this study (PR 24 LHT XT and PR 25 PS XT), commercially known as Pyrograf III ${ }^{\mathrm{TM}}$, were supplied by Applied Sciences, Inc. (ASI, Cedarville, OH, USA). Electrically conducting fibers, PR 24 LHT XT, in the form of a loose powder with a bulk density of $\sim 1.95 \mathrm{~g} / \mathrm{cm}^{3}$ and a highly graphitic outer wall layer, have an average diameter of $80 \mathrm{~nm}$. They have been heat-treated at temperatures of $1500{ }^{\circ} \mathrm{C}$. Electrically conducting fibers, PR 25 PS XT, with a bulk density of $\sim 0.032 \mathrm{~g} / \mathrm{cm}^{3}$ and an outer layer consisting on a disordered pyrolytically stripped layer with a large number of graphitic edge sites available along the length, have an average diameter of $120 \mathrm{~nm} \cdot{ }^{17,18}$ They have been heat-treated at 
temperatures of $600{ }^{\circ} \mathrm{C}$. Both types of CNFs had a debulking treatment in order to lower their respective bulk densities.

$\mathrm{PP} / \mathrm{CNF}$ nanocomposites were fabricated, under the same processing conditions, on a modular lab-scale intermeshing mini-co-rotating twin-screw extruder, with a screw diameter of $13 \mathrm{~mm}$, barrel length of $31 \mathrm{~cm}$ and an approximate L / D ratio of 26, coupled to a cylindrical rod dye of approximate $2.85 \mathrm{~mm}$ of diameter. The extruded $\mathrm{PP} / \mathrm{CNF}$ nanocomposites were then pelletized and pressed into compression-moulded with the appropriate geometries for electrical and rheological tests. A detailed description of the meltcompounding conditions and machining of samples has been previously published. ${ }^{19}$

The nomenclature used to designate the composites is summarized in Table 1.

\section{Characterization}

Morphological characterization and CNF dispersion of the composites were examined using a JEOL JSM-6400 scanning electron microscope (SEM) at an accelerating voltage of $20 \mathrm{kV}$. The samples were broken under cryogenic conditions and then sputter-coated with a thin layer of gold before testing.

Electrical characterization was performed by measuring the bulk resistance of ten rectangular replicates per sample with an automated Keithley 487 picoammeter/voltage source and then the total average was calculated. The samples' dimensions were $49 \mathrm{~mm}$ x $10 \mathrm{~mm}$ x $1 \mathrm{~mm}$. All the experiences were performed at room temperature in direct current (DC) by using the twoprobe method. The samples' extremities were painted with conductive silver paste. The volume conductivity in $\mathrm{S} \mathrm{m}^{-1}$ was calculated taken into account the geometrical characteristics of the samples. ${ }^{19}$

Viscoelastic characterization was performed using a controlled strain rheometer (ARES, TA Instruments) with parallel-plate geometry (25 mm diameter, $2 \mathrm{~mm}$ gap) at $190^{\circ} \mathrm{C}$. Complex 
viscosity $\left(\eta^{*}\right)$, storage modulus $\left(G^{\prime}\right)$, loss modulus $\left(G^{\prime}\right)$ ) and inverse of loss tangent $\left(G^{\prime} /\right.$ $\mathrm{G}^{\prime \prime}$ ) were measured as a function of frequency $(\omega)$. The rheological tests were performed in the linear viscoelastic region (LVE) where the modulus is independent of strain. The linear viscoelastic region was determined by a strain sweep before testing the viscoelasticity of the composites under a frequency test. At the end, frequency sweep measurements were set up in the frequency range from $1 \times 10^{-1}$ to $10^{2} \mathrm{rad} / \mathrm{s}$.

\section{RESULTS AND DISCUSSION}

\section{Morphological analysis}

The SEM observations of the $1.9 \%$ vol CNFs filled nanocomposites demonstrate that the two composites reveal different structures. PR 24 LHT XT composites, electrically conducting for $1.9 \%$ vol loading, show that CNFs are well dispersed, distributed and close enough to each other, Figure 1(a). PR 25 PS XT composites, in opposite, though show also well distributed and dispersed morphology, exhibit a larger distance between fibers for the same loading of $1.9 \%$ vol. This fact suggests the need of a larger content of CNFs to provide electrical conductive composites, Figure 1(b).

\section{Electrical properties in CNFs / PP nanocomposites}

The electrical volume conductivity of the neat PP and CNF/PP composites as a function of CNF concentration is represented in Figure 2. Each data point on the plot represents the average of 10 samples. Pure PP has an electrical conductivity of $2.22 \times 10^{-8} \mathrm{~S} \mathrm{~m}^{-1}$. PR 24 LHT XT composites increased by 9 orders of magnitude, approaching a value of $14.9 \mathrm{~S} \mathrm{~m}^{-1}$ for $2.4 \%$ vol loading, whereas PR 25 PS XT composites showed no relevant increase of the electrical conductivity for all filler loadings. The heat treatment at temperatures of $1500{ }^{\circ} \mathrm{C}$ of PR 24 fibres (LHT grade) with a more ordered structure on the fiber's surface and better intrinsic conductivity, together with the higher bulk density which allows better distribution 
and dispersion in the PP, unlike PR 25 fibers, demonstrate superior electrical conducting results for this particular polymer and processing method. ${ }^{20}$

The variation of the transport properties with dispersion state of carbon-based nanocomposites is usually understood in the framework of the percolation theory. ${ }^{21-23}$ According to this, the behavior of the conductivity can be described by the following power law relation:

$$
\sigma \propto\left(\phi-\phi_{c}\right)^{t}
$$

where $\sigma$ is the electrical conductivity, $\mathrm{t}$ is a critical exponent, $\Phi_{\mathrm{c}}$ the critical volume fraction and $\Phi$ the filler volume fraction. Experimental percolation threshold for PR 24 LHT XT composites is bounded between $\sim 0.2$ and $\sim 0.5 \%$ vol, as shown in Figure 2. More precisely, by means of equation 1 , a value of $0.42 \% \mathrm{vol} \pm 0,07$ is obtained. The critical exponent value $\sim 1,75$ is in agreement with the theoretical $3 \mathrm{D}$ values. The critical exponent points out that the conductivity is related to the formation of a $3 \mathrm{D}$ network that spans the system, whereas the experimental values of percolation threshold represent a deviation from theoretical prediction associated to the existence of small agglomerates, as previously discussed. ${ }^{19}$

\section{Rheological properties in CNFs / PP nanocomposites}

The frequency dependence of the shear storage modulus $\mathrm{G}^{\prime}$, the loss modulus $\mathrm{G}^{\prime \prime}$, inverse of the loss tangent $\mathrm{G}^{\prime} / \mathrm{G}^{\prime \prime}$, and complex viscosity $\eta^{*}$, for the two composites with different loadings of $\mathrm{CNF}$, at the temperature used during the extrusion, i. e., $190{ }^{\circ} \mathrm{C}$, are shown in Figures 3, 4, 5 and 6, respectively. Several common features can be observed. First, a reduction for the two lowest loadings 0.2 and $0.5 \%$ vol compared with the neat PP is observed in all rheological properties. In this regard, the CNFs may act as nucleating agents for PP and make the polymer chains to be well aligned and ordered. However, for higher 
loadings, the surface available for nucleating is huge and there are not enough polymer chains to go and crystallize on the fibers. ${ }^{24}$

The filled composites and the neat PP exhibit similar results due to shear-thinning effect in the high frequency region. ${ }^{25}$ Overall, it is accepted that, at low frequencies, viscoelastic behavior shows information about the formation of fibers' networks at a certain levels of reinforcement, ${ }^{12}$ while at high frequencies the rheological analysis reflects motions of short molecular chains independently of filler. ${ }^{26}$

Particularly in Figure 3, the storage modulus, G', which provides a measure of "stiffness", 27, 12, 14 is compared for all composites as a function of frequency. For PP / PR 24 LHT XT composites, Figure 3(a), for a frequency of $0.1 \mathrm{rad} / \mathrm{s}, \mathrm{G}^{\prime}$ exhibits an abrupt change in modulus between 0.5 and $0.9 \%$ vol with values of 21 and $860 \mathrm{~Pa}$, respectively, with a maximum of $15411 \mathrm{~Pa}$ for $2.4 \%$ vol. A total increase of three orders of magnitude therefore. This point indicates the creation of a continuous filler's network which restrains the longrange motions of the polymer chains. ${ }^{26}$ In addition, at loadings higher than $0.5 \%$ vol, the $\mathrm{G}^{\prime}$ is clearly less dependent on frequency than for lower volume fractions. This particular response is associated with the transition from liquid-like to solid-like viscoelastic behavior. ${ }^{12}$ It has been discussed in previous studies that dispersion plays a key role in the viscoelastic properties of CNT/polymer nanocomposites. In this study, PP / PR 24 LHT XT composites demonstrate to have a low-frequency slope of $\mathrm{G}^{\prime}$ at the highest loadings of CNFs, which has been associated to good dispersion. ${ }^{12}$

PP / PR 25 PS XT composites, on other hand, do not reveal significant changes in behavior compared to pure PP, Figure 3(b). Further, a modest increase of modulus with a maximum of $173 \mathrm{~Pa}$ for $2.4 \%$ vol loading is observed for $0.1 \mathrm{rad} / \mathrm{s}$. According to the above discussion, this behavior together with the frequency dependence of $\mathrm{G}^{\prime}$ for all volume fractions may 
indicate that PP / PR 25 LHT XT composites have not formed yet an interconnected structure even at the maximum loading of $2.4 \%$ vol.

The loss modulus, $\mathrm{G}^{\prime \prime}$, which provides a measure of viscous resistance to deformation, as a function of frequency, is shown in Figure 4. Consistently with storage modulus, at low frequencies $\mathrm{G}^{\prime \prime}$ increases with increasing CNF content for all composites, with exception of the two lowest loading contents of CNF 0.2 and $0.5 \%$ vol. On the other hand, the increase in $\mathrm{G}^{\prime \prime}$ is lower than the storage modulus $\mathrm{G}^{\prime}$ at a fixed CNF content. This lower behavior was already reported. ${ }^{26,27}$ Again, the increase is more pronounced for PP / PR 24 LHT XT composites, which above a content of $0.9 \%$ vol show a clear change in behavior compared to pure PP. This last circumstance is not observed for PP / PR 25 PS XT composites, which suggests that there is no evidence of interconnected nanofiber's networks.

Supplementary information about interaction between CNFs and the polymer can also be estimated through the inverse loss tangent $\left(\mathrm{G}^{\prime \prime} / \mathrm{G}^{\prime}\right)$, Figure 5, which relates elastic $\left(\mathrm{G}^{\prime}\right)$ with dissipative $\left(G^{\prime \prime}\right)$ characteristics of the composites. ${ }^{14}$ The curves follow the same trend of $G^{\prime}$ and $\mathrm{G}^{\prime \prime}$. Nevertheless, it is important to highlight the sharp variation between 0.5 and 0.9 vol \%, as it happens with $\mathrm{G}^{\prime}$ for the same content of CNF, in PP / PR 24 LHT XT composites.

The frequency dependence of the complex viscosity, $\eta^{*}$, for the PP / CNFs nanocomposites is shown in Figure 6. The pure PP shows a Newtonian plateau at low frequencies, whereas for PP / PR 24 LHT XT composites, from $0.5 \%$ vol the plateau decreases and yield stress appears, consistently with behaviors observed for $\mathrm{G}^{\prime}$ and $\mathrm{G}^{\prime \prime}$.

PP / PR 25 LHT XT composites, although show a clear variation in value of $\eta^{*}$ between 0.9 and $1.4 \%$ vol, do not change apparently the shape of the curve. 
Summarizing the quantitative assessment of the experimental rheological analysis, depending on the type of carbon nanofiber substantial differences can be appreciated between the two composites. PP / PR 24 LHT XT composites, consistently with theoretical predictions and previous experimental reports in CNTs based polymer composites, show a transition between liquid-like and solid-like: as the nanofiber content increases, the creation of some interconnected structure leads to a solid-like behavior $\left(\mathrm{G}^{\prime}>\mathrm{G}^{\prime \prime}\right)$, which explain the plateaus or independence behavior with frequency for $\mathrm{G}^{\prime}$ and $\mathrm{G}^{\prime \prime}$ at the lower frequencies. ${ }^{27,29}$

\section{Comparison of electrical and rheological behaviors in CNFs / PP nanocomposites}

Electrical and rheological correlations may constitute a route to understand composites' microstructure.

According to the electrical results, PR 24 LHT XT composites exhibit an abrupt transition from isolating to electrical conducting behavior, which can be described in the context of percolation theory, from contents of CNFs of $\sim 0.42 \%$ vol. In terms of microstructure, this fact is related to the formation of a $3 \mathrm{D} \mathrm{CNFs'} \mathrm{network} \mathrm{which} \mathrm{allows} \mathrm{electrical} \mathrm{transport.} \mathrm{PR}$ 25 LHT XT composites, on their hand, do not show isolating-to-conducting electrical transition.

First, in order to calculate the most appropriate rheological parameter to describe rheological thresholds, the normalized logarithm values of $\mathrm{G}^{\prime}, \mathrm{G}^{\prime \prime}, \mathrm{G}^{\prime} / \mathrm{G}^{\prime \prime}$ and $\eta^{*}$ are plotted and compared with the normalized logarithm values of electrical conductivity for PR 24 LHT XT composites in Figure 7. ${ }^{15}$ Though $\mathrm{G}^{\prime}$ is commonly reported as the most adequate rheological parameter to describe rheological thresholds, up to now this question is still under discussion and different assumptions have been reported in the literature: power-law dependence based on $\mathrm{G}^{\prime},{ }^{15,12,30}$ power-law dependence based on $\mathrm{G}^{\prime} / \mathrm{G}^{\prime \prime},{ }^{14,15}$ and even on $\eta^{*}{ }^{31}$ In Figure 7, apart the two first concentrations with negative values due to the reduced viscosity discussed 
above, the normalized logarithm values of $\mathrm{G}^{\prime \prime}$ and $\eta^{*}$ show a gradual increase with concentration when compared with $\mathrm{G}^{\prime}$ and mainly with $\mathrm{G}^{\prime} / \mathrm{G}^{\prime \prime}$ which demonstrates to be the most sensitive parameter to the rheological thresholds and the most adequate parameter for comparing with electrical conducting values from $0.9 \%$ vol. This is in accordance with the study by Kharchenko et. al, which uses the inverse of loss tangent to compare with electrical conductivity, ${ }^{14}$ and the study by Kota et. al, which concludes that $\eta^{*}$ and $\mathrm{G}^{\prime \prime}$, related to viscous response, are less sensitive than $\mathrm{G}^{\prime}$ and $\mathrm{G}^{\prime} / \mathrm{G}^{\prime \prime}$, related to the elastic response. ${ }^{15}$

In order to compare the rheological and electrical thresholds, a power-law was fitted to $\mathrm{G}^{\prime} /$ $\mathrm{G}^{\prime \prime}$ and $\mathrm{G}^{\prime}$. The equations used and the two rheological parameters, together with the determined values of $\sigma$, are listed in Table 2. As it can be seen, the rheological threshold based on $\mathrm{G}^{\prime} / \mathrm{G}^{\prime \prime}$ analysis is $\sim 0.49 \%$ vol whereas for $\mathrm{G}^{\prime}$ is $\sim 0.47 \% \mathrm{vol}$, which indicates that the rheological threshold occurs at a slight higher concentration than the electrical percolation threshold $(0.42 \% \mathrm{vol} \pm 0,07)$. The different values obtained for rheological and electrical thresholds in literature are cause of discussion. Some studies show that rheological threshold occurs after electrical percolation, referring that connectivity between fibers precedes rigidity percolation of the system. ${ }^{14}$ Others studies, nevertheless, point out the opposite, on the basis of an adequate combination of alignment, dispersion of the fillers and molecular weight of polymer matrix. $^{12}$

The exponents calculated on the basis of a normal power law relation, were 0.52 for $\mathrm{G}^{\prime} / \mathrm{G}^{\prime \prime}$ and 1.54 for $\mathrm{G}^{\prime}$. Even though for the electrical percolation theory the exponents are assumed to be universal with theoretical $3 \mathrm{D}$ values of $\sim 2$, a wide range of values have been reported for rheological thresholds based on $\mathrm{G}^{\prime}$ in polymer composites based on carbon nanotubes: $0.70,{ }^{12} 2.91,{ }^{31} 2.64$ and $2.59,{ }^{32}$ which suggests that $G^{\prime}$ or $G^{\prime} / G^{\prime \prime}$ follow different scaling laws to describe their volume fraction dependence when compared with electrical conducting $\sigma^{32}$ 


\section{CONCLUSIONS}

Two different CNFs were incorporated in in the same polypropylene (PP) matrix by twinscrew extrusion under the same processing conditions. Electrically, the two carbon nanofiber based polypropylene composites demonstrated to have different response: non-conducting and conducting as a function of volume fraction concentration. A large difference in the rheological behavior of both composites has been measured. Whereas the electrical conducting composites based on PR 24 LHT XT carbon nanofibers show liquid-like to solidlike transition which leads to the plateaus for $G^{\prime}, G^{\prime \prime}$ at low frequencies, the electrical isolating composites based on PR 25 PS XT carbon nanofibers remain practically unaltered in their rheological behavior when compared to the pure PP composites. This fact suggests that rheological analysis clearly differentiates electrical conducting from insulating performance for this particular type of systems. Furthermore, after comparing electrical conductivity and rheological analysis, it is concluded that $\mathrm{G}^{\prime} / \mathrm{G}^{\prime \prime}$ and in less extent $\mathrm{G}^{\prime}$ are the most appropriate rheological parameters for comparing with electrical behavior, which is consistent with previous works that identify elastic load rheological parameters as the best candidates to compare to the onset of electrical percolation. The rheological threshold fitted from $\mathrm{G}^{\prime} / \mathrm{G}^{\prime \prime}$ was found to be $\sim 0.5 \%$ vol, slightly higher than electrical percolation threshold $\sim 0.4 \%$ vol. Finally, the difference found between exponents in $G^{\prime} / G^{\prime \prime}$ and $G^{\prime}$ fittings, suggests different scaling laws to describe their volume fraction dependence when compared with electrical conductivity $\sigma$.

\section{ACKOWLEDGMENTS}

Financial support for this work has been provided by Consellería de Educación e Ordenación Universitaria, Xunta de Galicia through grant CN2011/008. 


\section{REFERENCES AND NOTES}

1 Kang, I.; Heung, Y.Y.; Kim, J.H.; Lee, J.W.; Gollapudi, R.; Subramaniam, S.; Narasimhadevara, S.; Hurd, D.; Kirikera, G.R.; Shanov, V.; Schulz, M.J.; Shi, D.; Boerio, J.; Mall, S.; Ruggles-Wren, M. Compos. Part B-Eng. 2006, 37, 382-394.

2 Burton, D.J.; Glasgow, D.G.; Lake, M.L.; Kwag, C.; Finegan, J.C.; In Repecka LSFF (ed) A Materials and Processes Odyssey, Books 1 and 2, vol 46. International Sampe Technical Conference Series 2001; pp 647-657.

3 Gordeyev, S.A.; Macedo, F.J.; Ferreira, J.A.; van Hattum, F.W.J.; Bernardo, C.A. Physica B. 2000, 279, 33-36.

4 Al-Saleh, M.H.; Sundararaj, U. Carbon. 2009, 47, 2-22.

5 Tibbetts, G.G.; Lake, M.L.; Strong, K.L.; Rice, B.P. Compos. Sci. Technol. 2007, 67, $1709-1718$.

6 Das, N.C.; Yamazaki, S.; Hikosaka, M.; Chaki, T.K.; Khastgir, D.; Chakraborty, A. Polym. Int. 2005, 54, 256-259.

7 Huang, J.C. Adv. Polym. Tech. 1995, 14, 137-150.

8 Lillehei, P.T.; Kim, J-W.; Gibbons, L.J.; Park, C. Nanotechnology. 2009, 20, 325708325714.

9 Gershon, A.L.; Cole, D.P.; Kota, A.K.; Bruck, H.A. J. Mater. Sci. 2010, 45, 6353-6364.

10 Schadler, L.S.; Giannaris, S.C.; Ajayan, P.M. Appl. Phys. Lett. 1998, 73, 3842-3844.

11 Fiedler, B.; Gojny, F.H.; Wichmann, M.H.G.; Nolte, M.C.M.; Schulte, K. Compos. Sci. Technol. 2006, 66, 3115-3125. 
12 Du, F.M.; Scogna, R.C.; Zhou, W.; Brand, S.; Fischer, J.E.; Winey, K.I. Macromolecules. 2004, 37, 9048-9055.

13 Wagener, R.; Reisinger, T.J.G. Polymer. 2003, 44, 7513-7518.

14 Kharchenko, S.B.; Douglas, J.F.; Obrzut, J.; Grulke, E.A.; Migler, K.B. Nat. Mater. 2004, $3,564-568$.

15 Kota, A.K.; Cipriano, B.H.; Duesterberg, M.K.; Gershon, A.L.; Powell, D.; Raghavan, S.R.; Bruck, H. A. Macromolecules. 2007, 40, 7400-7406.

16 Zhu, J.; Wei, S.; Yadav, A.; Guo, Z. Polymer. 2010, 51, 2643-2651.

17 Evora, M.C.; Klosterman, D.; Lafdi, K.; Li, L.; Abot, J. L. Carbon. 2010, 48, 2037-2046.

18 Tessonnier, J-P.; Rosenthal, D.; Hansen, T.W.; Hess, C.; Schuster, M.E.; Blume, R.; Girgsdies, F.; Pfaender, N.; Timpe, O.; Su, D.S.; Schloegl, R. Carbon. 2009, 47, 1779-1798.

19 Paleo, A.J.; van Hattum, F.W.J.; Pereira, J.; Rocha, J.G.; Silva, J.; Sencadas ,V.; LancerosMendez, S. Smart. Mater. Struct. 2010, 19, 065013-065019.

20 http://www.apsci.com

21 Bunde, A.; Havlin, S. In Fractals and disordered systems; Springer: New York, 1996; pp $27-8$.

22 Heaney, M.B. Phys. Rev. B. 1995, 52, 12477-12480.

23 Garboczi, E.J.; Snyder, K.A.; Douglas, J.F.; Thorpe, M.F. Phys. Rev. E. 1995, 52, 819828.

24 Kalaitzidou, K.; Fukushima, H.; Askeland, P.; Drzal, L. T. J. Mater. Sci. 2008, 43, $2895-$ 2907. 
25 Mutel, M.R.K. Utracki, L.A., Ed.; Carl Hanser: Munich, 1991, Chapter 12.

26 Ferry, J.D. In Viscoelastic Properties of Polymers; Wiley: New York, 1980.

27 Potschke, P.; Fornes, T.D.; Paul, D.R. Polymer. 2002, 43, 3247-3255.

28 Utracki, L.A. Polym. Composite. 1986, 7, 274-282.

29 Lozano, K.; Yang, S.Y.; Zeng, Q. J. Appl. Polym. Sci. 2004, 93, 155-162.

30 Cipiriano, B.H.; Kashiwagi, T.; Raghavan, S.R.; Yang, Y.; Grulke, E.A.; Yamamoto, K.; Shields, J.R.; Douglas, J.F. Polymer. 2007, 48, 6086-6096.

31 Martins, J.N.; Bassani, T.S.; Barra, G.M.O.; Oliveira, R.V.B. Polym. Int. 2011, 60, 430435.

32 Huang, C.L.; Wang, C. Carbon. 2011, 49, 2334-2344.

John Wiley \& Sons, Inc. 
FIGURE 1 SEM micrographs of $1.9 \%$ vol PP / CNFs composites: (a) PP / PR 24 LHT XT composites, (b) PP / PR 25 PS XT composites.

FIGURE 2 Electrical conductivity values versus volume fraction loadings of CNFs and corresponding fit using equation $1 . R 2$ is 0.99 for the PP/ PR 24 LHT XT composites fitting.

FIGURE 3 Storage moduli of (a) PP / PR24LHTXT composites and (b) PP / PR25PSXT composites as a function of frequency at $190^{\circ} \mathrm{C}$.

FIGURE 4 Loss moduli of (a) PP / PR24LHTXT composites and (b) PP / PR25PSXT composites as a function of frequency at $190^{\circ} \mathrm{C}$.

FIGURE 5 Inverse loss tangent of (a) PP / PR24LHTXT composites and (b) PP / PR25PSXT composites as a function of frequency at $190^{\circ} \mathrm{C}$.

FIGURE 6 Complex viscosity of (a) PP / PR24LHTXT composites and (b) PP / PR25PSXT composites as a function of frequency at $190^{\circ} \mathrm{C}$.

FIGURE 7 The normalized log values of electrical conductivity $\sigma$, storage modulus $\mathrm{G}^{\prime}$, loss modulus $\mathrm{G}^{\prime \prime}$, inverse loss tangent $\mathrm{G}^{\prime} / \mathrm{G}^{\prime \prime}$ and complex viscosity $\eta^{*}$ as a function of PR24LHTXT's concentration. The rheological data corresponds to a frequency of $0.1 \mathrm{rad} / \mathrm{s}$. The dashed line is to guide the eyes.

Table 1. Composites' nomenclature

Table 2. Fitting results for power-law relations in electrical and rheological experiences for PP / PR 24 LHT XT composites 


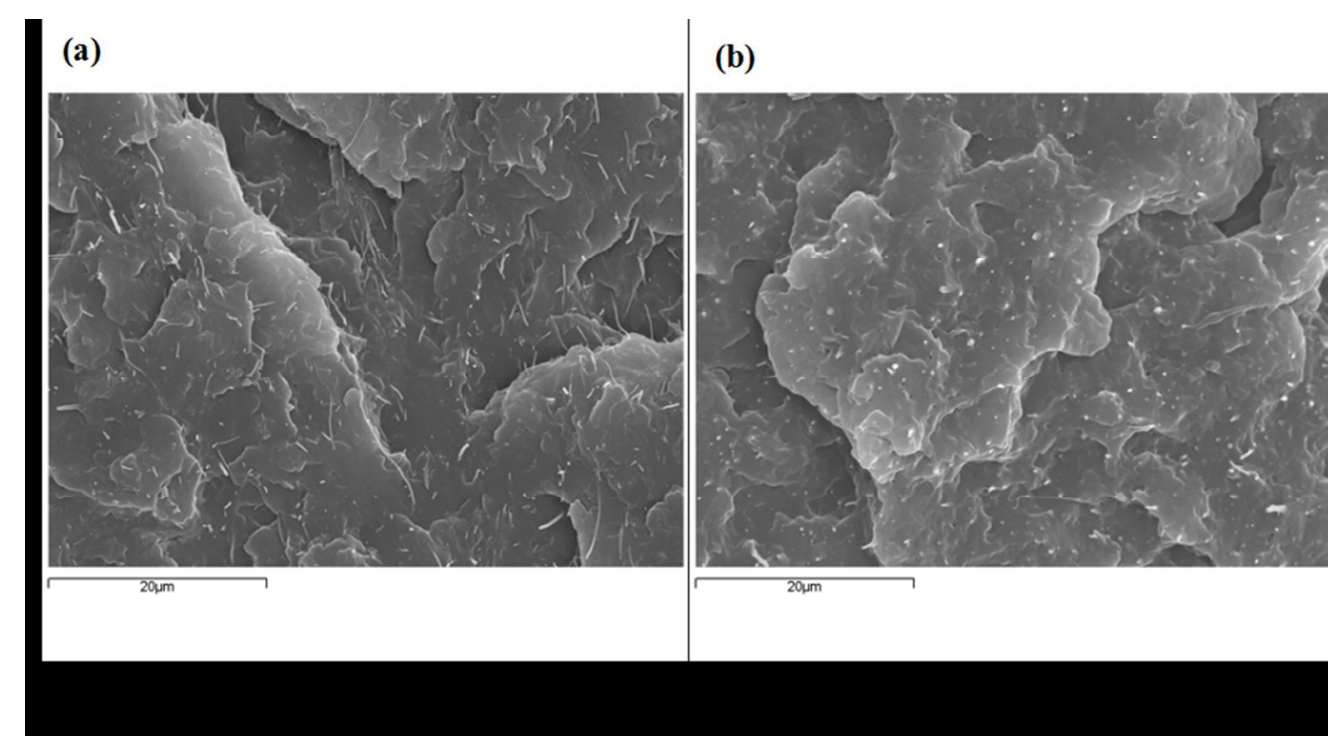

FIGURE 1 SEM micrographs of 1.9 \% vol PP / CNFs composites: (a) PP / PR 24 LHT XT composites, (b) PP / PR 25 PS XT composites. $163 \times 90 \mathrm{~mm}(150 \times 150 \mathrm{DPI})$

John Wiley \& Sons, Inc. 
FIGURE 2 Electrical conductivity values versus volume fraction loadings of CNFs and corresponding fit using equation 1. R2 is 0.99 for the PP/ PR 24 LHT XT composites fitting. $202 \times 141 \mathrm{~mm}(300 \times 300 \mathrm{DPI})$ 

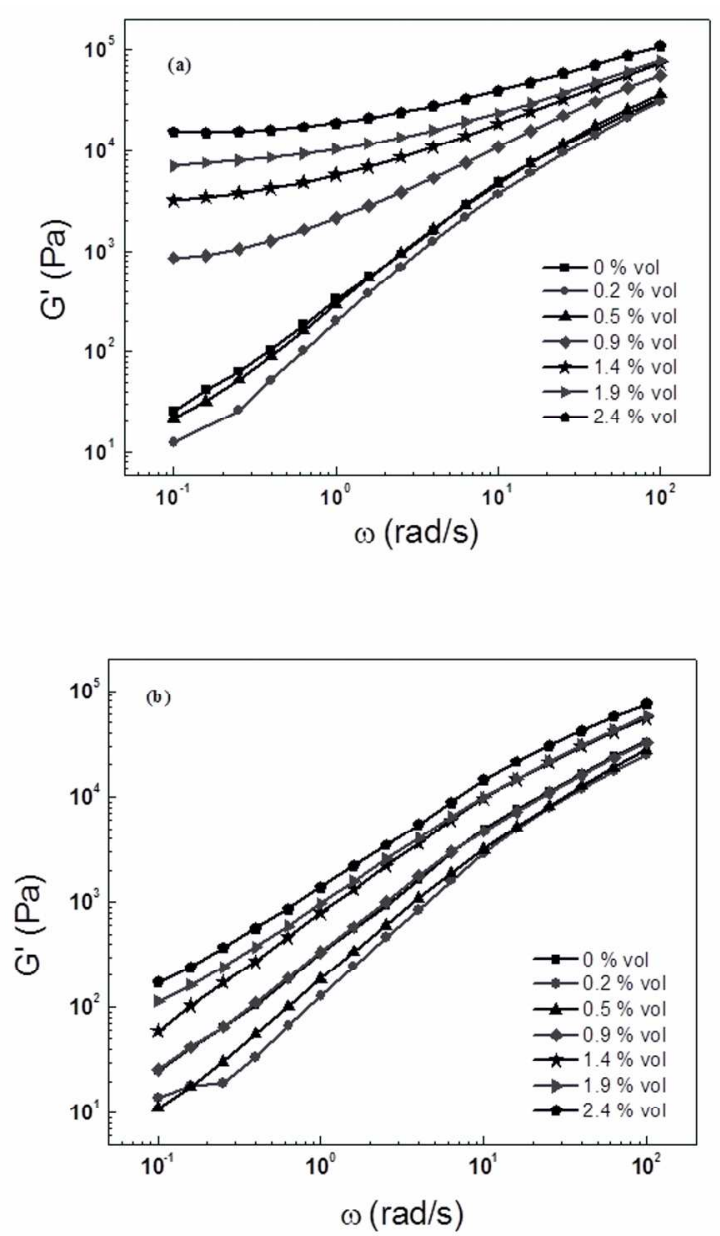

FIGURE 3 Storage moduli of (a) PP / PR24LHTXT composites and (b) PP / PR25PSXT composites as a function of frequency at $190^{\circ} \mathrm{C}$ $163 \times 172 \mathrm{~mm}(300 \times 300 \mathrm{DPI})$

John Wiley \& Sons, Inc. 

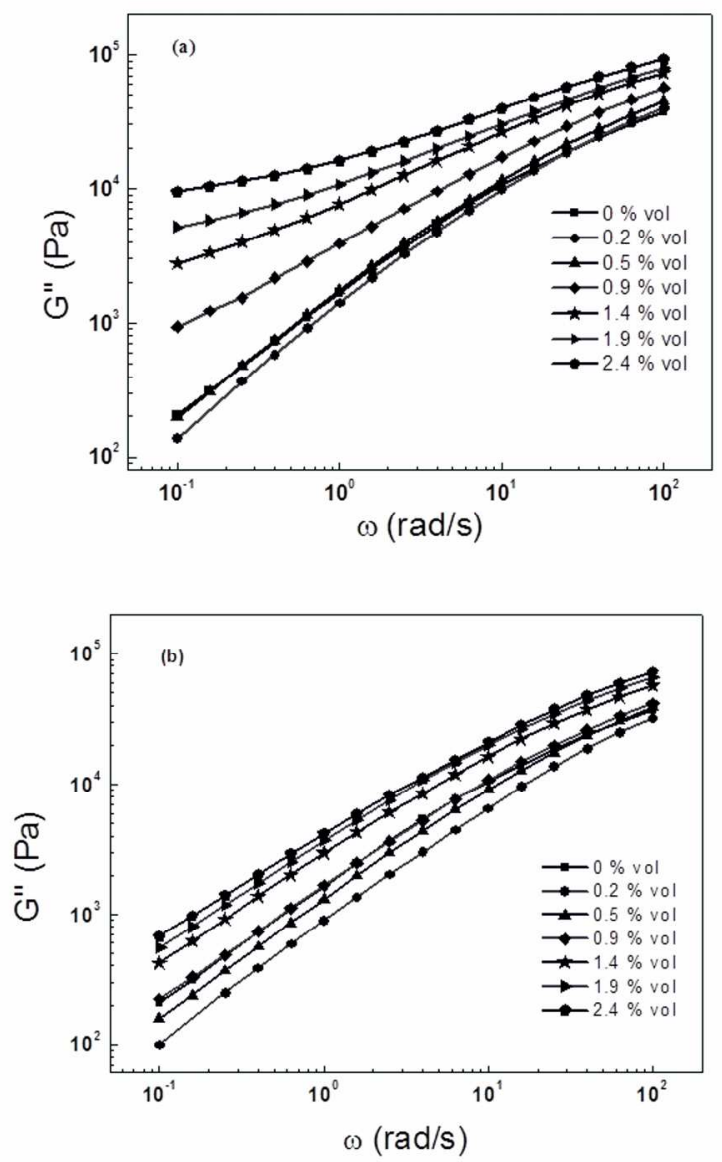

FIGURE 4 Loss moduli of (a) PP / PR24LHTXT composites and (b) PP / PR25PSXT composites as a function of frequency at $190^{\circ} \mathrm{C}$. $163 \times 174 \mathrm{~mm}(300 \times 300 \mathrm{DPI})$ 

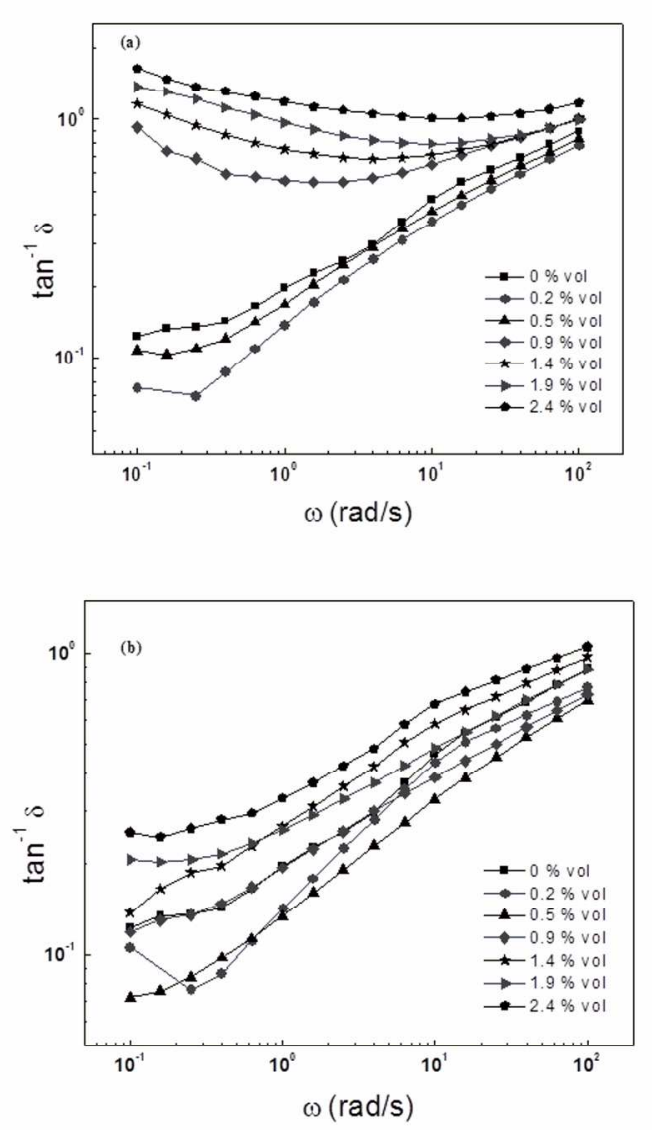

FIGURE 5 Inverse loss tangent of (a) PP / PR24LHTXT composites and (b) PP / PR25PSXT composites as a function of frequency at $190^{\circ} \mathrm{C}$. $163 \times 171 \mathrm{~mm}(300 \times 300 \mathrm{DPI})$

John Wiley \& Sons, Inc. 


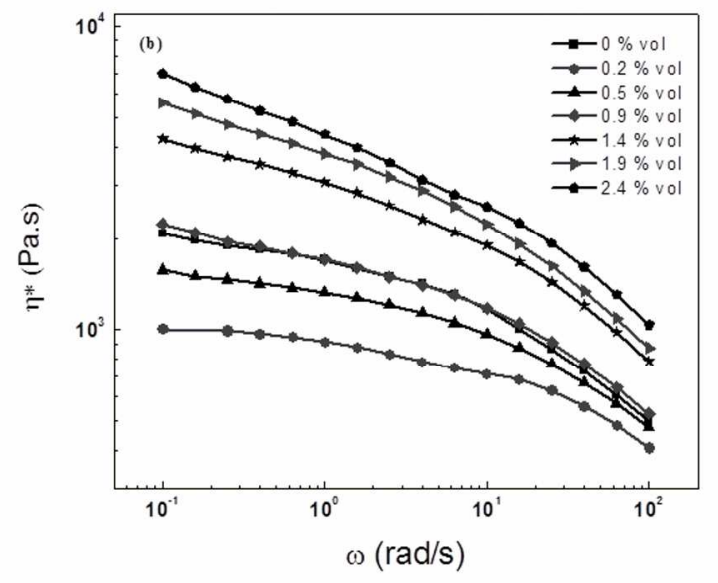

FIGURE 6 Complex viscosity of (a) PP / PR24LHTXT composites and (b) PP / PR25PSXT composites as a function of frequency at $190^{\circ} \mathrm{C}$. $163 \times 183 \mathrm{~mm}(300 \times 300 \mathrm{DPI})$ 


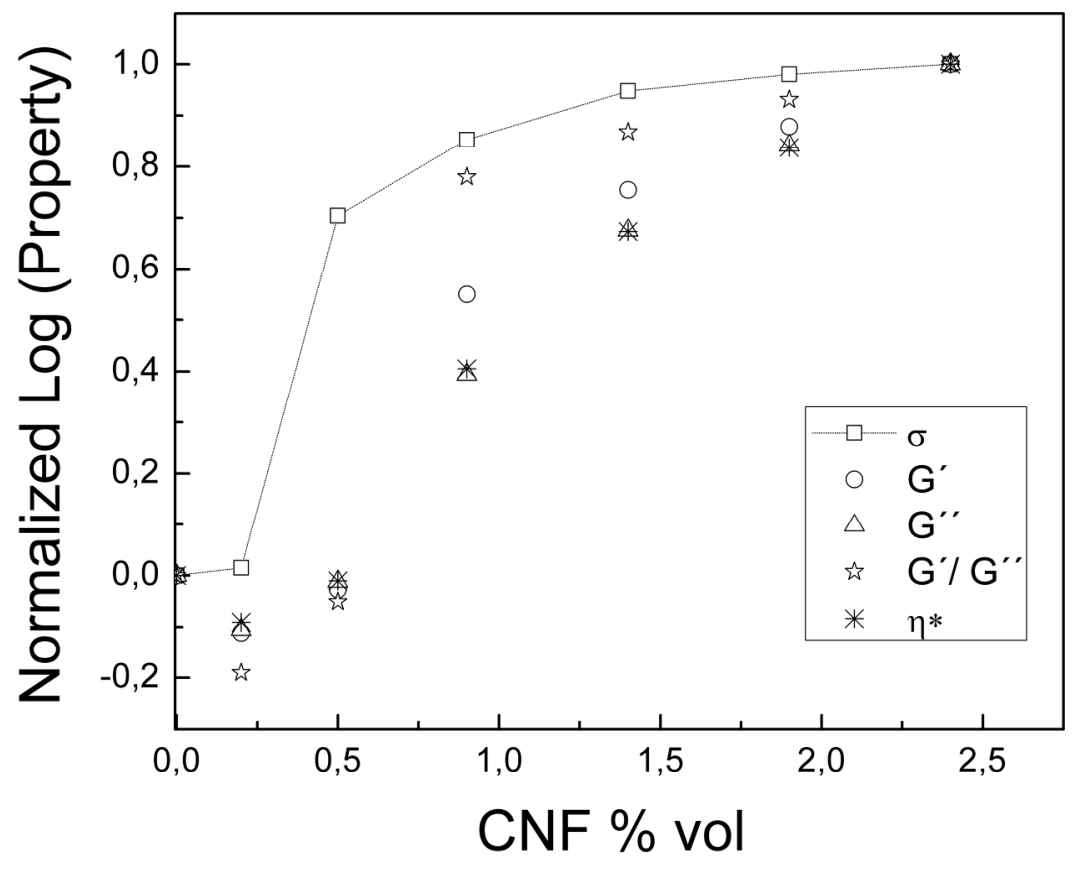

FIGURE 7 The normalized log values of electrical conductivity $\sigma$, storage modulus G', loss modulus G' ', inverse loss tangent $G^{\prime} / G^{\prime}$ ' and complex viscosity $\eta^{*}$ as a function of PR24LHTXT's concentration. The rheological data corresponds to a frequency of $0.1 \mathrm{rad} / \mathrm{s}$. The dashed line is to guide the eyes. $221 \times 169 \mathrm{~mm}(300 \times 300 \mathrm{DPI})$ 
Table 1. Composites' Nomenclature

\begin{tabular}{ccccc}
\hline $\begin{array}{c}\text { Composite } \\
\mathrm{Nr}\end{array}$ & CNF type & CNF grade & Polypropylene & CNFs Loadings \\
\hline 1 & PR24 & LHT XT & Borealis EE002AE & $0.2,0.5,0.9,1.4,1.9,2.4 \%$ vol \\
2 & PR25 & PS XT & & \\
\hline
\end{tabular}


Table 2. Fitting results for power-law relations in electrical and rheological experiencies

\begin{tabular}{cccc}
\hline Power-law relation & Percolation threshold, $\phi c($ vol \%) & $\mathrm{t}$ & $\mathrm{R} 2$ \\
\hline$\sigma \alpha\left(\phi-\phi_{c}, \sigma\right)^{\mathrm{t}}$ & 0.42 & 1.75 & 0.99 \\
$\mathrm{G}^{\prime} / \mathrm{G}^{\prime \prime} \alpha\left(\phi-\phi_{c}, \mathrm{G}^{\prime} / \mathrm{G}^{\prime \prime}\right)^{\mathrm{t}}$ & & & 0.99 \\
$\mathrm{G}^{\prime} \alpha\left(\phi-\phi_{c}, \mathrm{G}^{\prime}\right)^{\mathrm{t}}$ & 0.49 & 0.52 & 0.99 \\
\hline
\end{tabular}

14

16

17 